\title{
Pengaruh E-Module Speaking Berbasis Website Untuk Meningkatkan Keterampilan Berbicara
}

(Survei Pada Pendaftaran Situs Kursus Kampung Inggris Pare)

\author{
Wawan Herry Setyawan, Tantin Nawangsari \\ wawansetyawan@uniska-kediri.ac.id, 05nawang@gmailcom \\ Universitas Islam Kadiri, Kediri, Indodesia
}

Received: 12 Januari 2021; Revised: 26 Februari 2021; Accepted: 28 April 2021

DOI: http://dx.doi.org/10.37905/aksara.7.2.339-346.2021

\begin{abstract}
Abstrak
Tujuan dari penelitian ini adalah 1) untuk mengetahui kelayakan e-modul untuk meningkatkan keterampilan berbicara peserta didik dan 2) untuk mengetahui keefektifan e-modul untuk meningkatkan keterampilan berbicara peserta didik. Penelitian ini merupakan penelitian pengembangan dengan desain Research \& Development (R\&D) dengan pendekatan Borg \& Gall. Tahapan yang dilakukan dalam tujuh tahap yaitu: 1) Penelitian dan Pengumpulan Informasi, 2) Perencanaan, 3) Pengembangan Bentuk Produk Asli, 4) Pengujian Bidang Awal Produk, 5) Revisi Produk Awal untuk Menghasilkan Produk Utama, 6) Menguji Bidang Produk Utama, dan 7) Revisi Produksi Utama Menghasilkan Produk Operasional. Hasil penelitian menunjukkan bahwa dari penilaian para ahli diperoleh hasil pengukuran $92 \%$ dengan kategori nilai $81 \%-100 \%$ valid. Hal tersebut menunjukkan bahwa modul e-learning sangat sesuai untuk proses belajar mengajar sebagai hasil evaluasi pre-test dan post-test. Nilai rata-rata hasil belajar pada Pre Test 70,00 $<$ Post Test 90,00, nilai Sig. (2-tailed) adalah 0,000 <0,05, maka H0 ditolak dan Ha diterima. Sehingga dapat disimpulkan bahwa aplikasi e-modul Speaking on website by (Zoom) sangat berpengaruh dan efektif untuk diterapkan dalam sistem pembelajaran online di Kampung Course Pare-Kediri.
\end{abstract}

Kata Kunci: Pengembangan E-Modul, Keterampilan Berbicara, Situs Web Zoom

\section{Abstract}

The aimed of this research was 1) to know the feasibility of e-Module to improve learners' speaking skill. This research was a development research using Research \& Development $(R \& D)$ design by using Borg \& Gall approach. The stages were carried out in seven steps such as: 1) Research and Information Collection, 2) Planning, 3) Developing the Original Product Form, 4) Testing The Field of Product Scratch, 5) Initial Product Revision to Produce the Main Product, 6) Test The Main Product Field, and 7) Major Production Revisions Produce Operational Products. The result showed that from assessment by experts, the measurement results were $92 \%$ with a category value of $81 \%-100 \%$ valid. It showed that the e-learning module was very suitable for the teaching and learning process as the result of the pre-test and post-test evaluations. The average value of learning outcomes on the Pre Test $70.00<$ Post Test 90.00, the value of Sig. (2-tailed) is $0.000<0.05$, then $\mathrm{HO}$ is rejected and $\mathrm{Ha}$ is accepted. So, it can be concluded that the e-module Speaking on website by (Zoom) application was very influential and effective to be applied in the online learning system at Kampung Course Pare-Kediri.

Kata Kunci: Pengembangan E-Modul, Keterampilan Berbicara, Situs Web Zoom 


\section{PENDAHULUAN}

Kampung Inggris dikenal sebagai tempat yang ramai dikunjungi pengunjung untuk belajar Pendidikan Bahasa Inggris. Bahasa Inggris adalah bahasa resmi dari 45 negara di dunia. Dan bahasa Inggris dipelajari oleh banyak negara, termasuk Indonesia. Pendidikan Bahasa Inggris merupakan kebutuhan mendasar bagi semua orang, terutama bagi pelajar. Alasan mahasiswa berkomunikasi menggunakan Bahasa Asing (Inggris) adalah mendapatkan soft skill yang berharga, yang menjadi pertimbangan bagi penerima lapangan kerja. Juga, diperlukan keterampilan untuk bekerja dengan baik dalam wawancara kerja dan dalam pekerjaan mereka (Harianto et al., 2020). Lebih lanjut, Pembelajaran Bahasa Inggris dipusatkan pada empat keterampilan utama: mendengarkan, berbicara, membaca, dan menulis (Herry Setyawan et al., 2019). Keterampilan ini harus ditangani dengan cara yang membantu siswa memenuhi standar yang di tetapkan untuk mereka dan mengembangkan kompetensi komunikatif mereka secara bertahap terutama berbicara. Berbicara merupakan salah satu keterampilan terpenting untuk dikembangkan dan ditingkatkan sebagai sarana komunikasi yang efektif (Mary, 2019). Menurut Setyawan et al., (2018), kesulitan siswa dalam mengaplikasikan komunikasi bahasa Inggris secara lisan menjadi bagian masalah yang mengkhawatirkan, terutama dalam berbicara. Keterampilan berbicara merupakan keterampilan yang paling sulit dicapai oleh pembelajar bahasa. Berbicara adalah hal yang paling terlihat dalam belajar bahasa dibandingkan dengan keterampilan lain seperti menulis, mendengarkan, dan membaca. Berbicara merupakan proses peningkatan bahasa komunikatif (Rane, 2011). Beberapa hal untuk menentukan kemampuan berbicara adalah dengan meningkatkan kemampuan bahasa yang baik, meningkatkan perbendaharaan kata dengan banyak membaca dan menulis, serta melatih keterampilan mendengarkan.

Pentingnya strategi pembelajaran bagi guru dan siswa dalam proses pembelajaran adalah strategi pembelajaran memberikan kesan yang berbeda kepada siswa ketika mengikuti proses pembelajaran (W. H. Setyawan, 2017). Selama ini pembelajaran berbicara hanya diajarkan secara sederhana yaitu siswa diberikan materi tertulis dan diminta untuk menulis dengan instruksi kemudian pada praktek berbicara menanggapi kenyataan tersebut, perlu menggunakan strategi pembelajaran yang sesuai dengan karakteristik siswa. Sehingga siswa akan merasa senang dan tidak bosan mengikuti proses pembelajaran karena siswa yang memiliki motivasi tinggi cenderung memiliki banyak energi (Rifai et al., 2020). Selain itu, strategi pembelajaran yang tepat akan mendukung kegiatan pembelajaran yang kondusif dan dapat mempengaruhi peningkatan prestasi belajar siswa. Salah satunya adalah strategi pembelajaran menggunakan E-Module yang sangat efektif selama Pandemi Covid -19 ini.

Pandemic Covid -19 menghadirkan banyak Kursus Bahasa Inggris di Kampung Iggris Pare-Kediri, menutup akses belajar secara offline, dan beralih ke pembelajaran online dengan memfasilitasi proses belajar siswa E-Module. Namun, modul yang digunakan harus memenuhi kriteria kelayakan dan efektivitas yang telah divalidasi dan disetujui oleh Penguji. Modul merupakan bahan ajar yang cukup kuat untuk digunakan sebagai bahan ajar dan salah satu cara pengorganisasian materi pembelajaran (Soeprajitno et al., 2019). Modul adalah program kegiatan belajar mengajar (KBM) terkecil, Modul terintegrasi akan 
memenuhi syarat sebagai 1) Berbagai tujuan instruksional umum akan didorong oleh pencapaian. 2) Topik yang akan dijadikan dasar proses belajar-mengajar. 3) Berbagai tujuan pembelajaran khusus yang ingin dicapai siswa. 4) Peran guru dalam proses belajar mengajar. 5) Kegiatan belajar yang harus diselesaikan dan kehidupan siswa tertata 6) Berbagai lembar kerja yang harus diisi siswa dan 7) Kegiatan evaluasi akan dilakukan selama berjalannya kegiatan belajar mengajar(GonzalezLlorente et al., 2019). Sebagai tutor yang melakukan kegiatan pembelajaran online dengan menggunakan e-Module, tutor akan fokus pada materi konten, strategi desain, dan model pembelajaran. Oleh karena itu modul pembelajaran berfungsi sebagai pembimbing dalam pengembangan pembelajaran dengan membuat modul dengan materi konten yang dibutuhkan siswa dan diharapkan dapat meningkatkan kemampuan berbicara mereka. Berdasarkan latar belakang yang diuraikan di atas. Peneliti tertarik untuk meneliti, "Pengaruh e-Module Berbasis Website Speaking untuk Meningkatkan Keterampilan Berbicara (Survei Pendaftar di Situs Kampung Course).

\section{METODE}

Penelitian ini merupakan penelitian pengembangan dengan rancangan Research \& Development (R\&D) dengan pendekatan (Borg \& Gall, 1984). Tahapan yang dilakukan dalam tujuh tahap yaitu: 1) Penelitian dan Pengumpulan Informasi, 2) Perencanaan, 3) Pengembangan Bentuk Produk Asli, 4) Pengujian Bidang Gores Produk, 5) Revisi Produk Awal untuk Menghasilkan Produk Utama, 6) Menguji Bidang Produk Utama, dan 7) Revisi Produksi Utama Menghasilkan Produk Operasional. Subjek tes dalam penelitian ini dan pengembang penilaian otentik meliputi ahli desain, ahli materi, ahli bahasa dan siswa. Untuk mengetahui tingkat validitas produk yang dikembangkan, peneliti menggunakan metode validasi eksternal yaitu dengan meminta tanggapan dari para ahli yang memiliki kualifikasi doktor di bidangnya. Tanggapan lebih lanjut dari pengguna

yaitu siswa setelah menggunakan product development. Hasil tanggapan validator ahli dan pengguna melalui kuesioner dianalisis dengan menggunakan rumus statistik non parametrik. Uji reliabilitas instrumen asesmen, peneliti menggunakan SPSS 22.

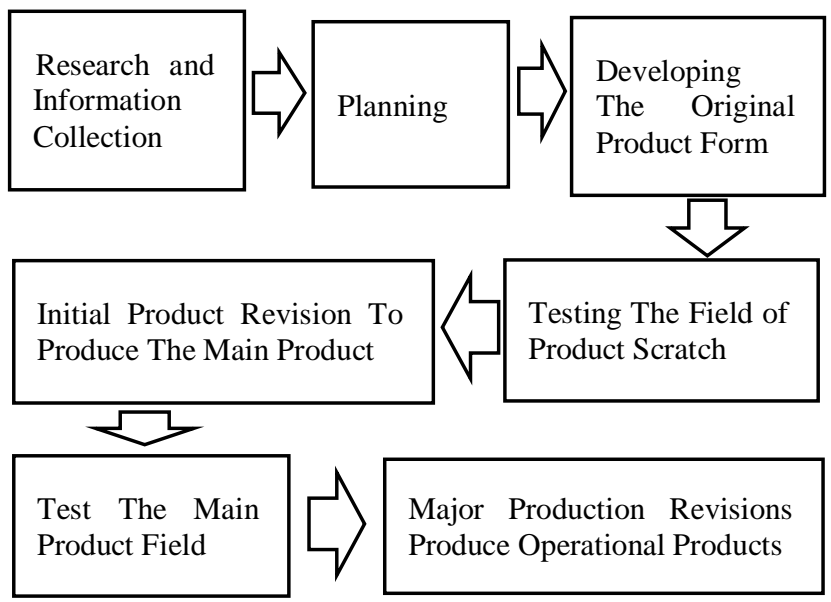

Gambar 1 Skema Penelitian dan Pengembangan oleh Borg dan Gall (1983). 


\section{HASIL DAN PEMBAHASAN \\ Kelayakan Pembelajaran e-Modul}

Untuk mengetahui kelayakan modul pembelajaran melalui aplikasi zoom. Dalam penelitian ini digunakan 7 langkah dari (Gall et al., 1996)untuk mengetahui prosedur pengembangan:

1. Penentuan Kelayakan Modul E. Tiga validasi ahli dan uji coba lapangan skala kecil dilakukan: Kriteria kelayakan pakar desain, ditemukan 92\% termasuk dalam kriteria kelayakan.

2. Perencanaan: Hasil penelitian menunjukkan bahwa peneliti membuat rumusan tujuan pembelajaran, menyusun materi materi, penyusunan, instrumen evaluasi, media penulisan skrip.

3. Mengembangkan Bentuk Produk Asli: Pembuatan produk media pembelajaran berbasis website dengan aplikasi pendukung zoom rapat langkah-langkah yang dilakukan adalah: a. Membuat sampul depan dan sampul belakang. cover dibuat dengan tujuan untuk menampilkan identitas e-modul agar calon peserta mendapatkan informasi apa yang dibutuhkan siswa, b. Pengembangan selanjutnya adalah pembuatan daftar isi agar materi bagian-bagian dari media pembelajaran tersebut dapat dibuat. terorganisir dengan baik. pengembangan dengan membuat tata letak. Layout dibuat dengan aspek warna secara utuh dan komposisi, c. Layout yang telah selesai dibuat kemudian diisi dengan materi interaksi antara tutor dan siswa. Materi dalam e-modul pembelajaran berbicara ini terdiri dari 14 sub materi yaitu meliputi latihan, angka, waktu menceritakan, hari dan angka, tanggal dan tahun, kata ganti, kalimat, kegiatan sehari-hari, kosakata, keluarga, orang mendeskripsikan, arah, bagian dari rumah dan rumah idaman saya, dan d. Setelah tahap materi, kemudian diberikan gambar yang dapat mendukung materi tersebut.

4. Menguji Bidang Awal Produk: a. Sebuah. Uji Coba Perorangan: Berdasarkan persentasenya $100 \%$. Sehingga setelah dikonversikan ke skala 1 dan persentase level $100 \%$ berada pada level yang baik sehingga E-Module layak digunakan dalam pembelajaran. b. Rekapitulasi Hasil Uji Coba Individual One to One pada 5 Siswa: persentase $86 \%$ pada bobot tiap pilihan adalah 1, maka tingkat pencapaiannya adalah $86 \%$ dengan kualifikasi baik.

5. Revisi Produk Awal untuk Menghasilkan Produk Utama: Kriteria kelayakan ahli desain, ditemukan 92\% termasuk dalam kriteria kelayakan. Revisi Produk: a. Pada poin 1 ahli desain menyatakan bahwa tujuan pada e-Module harus diubah secara lebih spesifik dan lebih jelas, agar calon mahasiswa mampu memahami maks dan tujuan penulis dalam membuat e-Module berbicara level 1, 2 Pada point 2 ahli materi menyatakan bahwa materi yang disajikan masih memiliki kekurangan pada penambahan materi perluasan seperti mind mapping, vocabularies dan brainstorming, 3. Pada point 12 ahli menyatakan bahwa kesesuaian ukuran modul dengan standar iso lebih baik. dihapuskan, karena tidak pantas atau tidak pantas. 
6. Tes Bidang Produk Utama: Presentasi Data Kelompok Lapangan, dilakukan uji coba lapangan yang diikuti oleh 15 siswa. persentase $86 \%$ pada bobot tiap pilihan adalah 1, maka tingkat pencapaiannya adalah 86\% dengan kualifikasi baik. sehingga E-Module tidak perlu direvisi.

7. Revisi Produksi Utama Menghasilkan Produk Operasional: Revisi Tahap I: Revisi pertama mengacu pada saran, komentar, dan validasi hasil ahli materi dan ahli desain. Revisi Tahap II: Revisi Tahap II dilakukan dengan mengacu pada saran, komentar, dan hasil pengamatan selama uji coba produk dan wawancara pengguna. Hasil Produk: Pengembangan produk merupakan proses pembuatan modul pembelajaran bahasa Inggris. Hasil pengembangan e-Module adalah sebagai berikut: Judul Buku (mastering on Listening and Speaking Conversation, Bentuk buku (Persegi Panjang), Ukuran buku (A5, Ukuran tulisan: Sampul (16), Isi Buku c. bahan (12), Jenis tulisan (Times New Roman) Warna tulisan Sampul (kombinasi), Jenis gambar (Kartun dan gambar) Perangkat lunak pendukung (Microsoft Word)

\section{Efektivitas Modul Pembelajaran}

Tabel 1 Ranks

\begin{tabular}{ll|c|c|c|}
\hline & $\mathrm{N}$ & Mean Rank & Sum of Ranks \\
\hline POSTEST & Negative Ranks & $0^{\mathrm{a}}$ & .00 & .00 \\
PRETEST & Positive Ranks & $15^{\mathrm{b}}$ & 8.00 & 120.00 \\
& Ties & $0^{\mathrm{c}}$ & & \\
& Total & 15 & & \\
\multicolumn{4}{|l}{} \\
a. POSTEST < PRETEST \\
b. POSTEST $>$ PRETEST \\
c. POSTEST = PRETEST
\end{tabular}

Untuk mengukur tingkat keefektifan modul pembelajaran melalui teks WhatsApp by Wilcoxon. Berdasarkan keluaran SPSS 22 terlihat bahwa Asymp. Sig. (2-tailed) adalah 0,01. Nilai 0,01 lebih rendah dari 0,05 atau 5\%. Ho ditolak dan Ha diterima yang artinya terdapat perbedaan rata-rata hasil berbicara developer e-Module antara pre-test dan post-test.

Table 2 Test Statistical

\begin{tabular}{|c|c|}
\hline & $\begin{array}{c}\text { POSTEST } \\
\text { PRE-TEST }\end{array}$ \\
\hline $\mathrm{Z}$ & $-3.413 \mathrm{~b}$ \\
$\begin{array}{c}\text { Asymp. Sig. } \\
\text { (2-tailed) }\end{array}$ & .001 \\
\hline
\end{tabular}

a. Wilcoxon Signed Ranks Test

b. Based on negative ranks. 


\section{PEMBAHASAN}

Pengembangan Speaking e-Module bertujuan untuk meningkatkan pemahaman siswa, khususnya untuk meningkatkan kemampuan berbicara dan memfasilitasi proses belajar siswa di rumah selama pandemi Covid-19. Setelah melalui beberapa tahapan validitas dan uji coba yang dijelaskan sebelumnya, media pembelajaran e-modul hasil pengembangan ini sudah layak digunakan. Total hasil validasi data berbicara e-modul tiap aspek dan hasil validasi data berbicara e-modul untuk masing-masing validator sebagai ahli materi yang diperoleh hasil yang sama memenuhi klasifikasi sangat baik dengan persentase 92\%. Artinya itu adalah kriteria yang memenuhi syarat. Hal ini relevan dalam penelitian Handoyono et.al (2020), Hasil uji kelayakan e-Module pada sistem rem oleh ahli materi mendapatkan nilai $81 \%$ dikategorikan sangat baik, oleh ahli media $85 \%$ dikategorikan sangat baik. bagus, dengan uji coba kelompok. Kecil, 83\%, sangat baik, dan dengan uji coba kelompok besar, nilai 79\% adalah baik. Dari hasil pengujian diatas dapat disimpulkan bahwa e-Module yang dikembangkan layak untuk digunakan dalam pembelajaran berbasis website.

E-Module ini dapat digunakan siswa untuk belajar di sekolah atau di rumah. Siswa menggunakan media pembelajarannya, dan siswa diberikan keleluasaan untuk menentukan kecepatan belajar dan memilih urutan kegiatan pembelajaran sesuai dengan kebutuhan siswa serta e-Module dapat mendampingi proses pembelajaran karena kualitas penggunaan berdasarkan hasil. Keefektifan e-Module dan hasil uji non parametrik dalam penelitian ini. Didapatkan bahwa nilai sig 0,00 lebih rendah dari 0,05 atau 5\%. Hasil ini sejalan dengan penelitian Nafi'ah \& Suparman (2019) dan . Hasilnya menunjukkan bahwa e-modul layak oleh ahli materi dan ahli media. Skor rata-rata validasi ahli materi mencapai 4,99 dengan kategori sangat baik, sedangkan skor validasi ahli media mencapai 4,86 dengan kategori sangat baik. e-Modul mencakup praktik berdasarkan tanggapan siswa dari uji coba skala kecil dan skala besar. Rata-rata nilai praktik tes skala kecil mencapai 4,44 dengan kategori sangat baik. Sedangkan nilai praktikum tes skala besar mencapai 4,45 dengan kategori sangat baik. e-Modules dapat digunakan untuk siswa yang memiliki tingkat kemampuan tinggi, sedangkan siswa yang memiliki tingkat kemampuan sedang membutuhkan bimbingan. Dengan modul e-speaking ini, siswa diberi kebebasan untuk mencari sumber informasi atau materi pemecahan masalah terkait materi yang mereka butuhkan. Penggunaan e-Module diharapkan dapat meningkatkan kemampuan berbicara siswa dan membiasakan siswa untuk memaksimalkan teknologi internet dalam pembelajaran.

\section{PENUTUP}

Berdasarkan hasil penelitian di atas menunjukkan 1) Tingkat kelayakan emodul berbicara 1 berdasarkan tinjauan ahli menyatakan hasil $92 \%$ data kesimpulan ahli pada tabel 4.2, terbukti layak atau valid sehingga E-Modul layak digunakan untuk pembelajaran berbicara online level 1 Berdasarkan website dan aplikasi zoom dan 2) Keefektifan e-Module Speaking berbasis website 1 Based untuk meningkatkan kemampuan berbicara siswa telah memenuhi syarat validitas pada data uji coba lapangan dan analisis dengan menggunakan uji Wilcoxon diperoleh hasil sebesar 0,00 yang artinya nilai <0,05 bahwa terbukti efektif. 


\section{DAFTAR PUSTAKA}

Borg, W. R., \& Gall, M. D. (1984). Educational research: An introduction.

Gall, M. D., Borg, W. R., \& Gall, J. P. (1996). Educational research: An introduction. Longman Publishing.

Gonzalez-Llorente, J., Lidtke, A. A., Hatanaka, K., Kawauchi, R., \& Okuyama, K.I. (2019). Solar Module Integrated Converters as Power Generator in Small Spacecrafts: Design and Verification Approach. Aerospace, 6(5), 61.

Harianto, G. P., Rusijono, R., Masitoh, S., \& Setyawan, W. H. (2020). Collaborative-Cooperative Learning Model to Improve Theology Students'characters: Is it Effective? Jurnal Cakrawala Pendidikan, 39(2).

Herry Setyawan, W., Budiman, A., Septa Wihara, D., Setyarini, T., Nurdyansyah, Rahim, R., \& Barid Nizarudin Wajdi, M. (2019). The effect of an androidbased application on T-Mobile learning model to improve students' listening competence. Journal of Physics: Conference Series, 1175(1). https://doi.org/10.1088/1742-6596/1175/1/012217

Mary, L. (2019). Significance of Prosody for Speaker, Language, Emotion, and Speech Recognition. In Extraction of Prosody for Automatic Speaker, Language, Emotion and Speech Recognition (pp. 1-22). Springer. https://link.springer.com/chapter/10.1007/978-3-319-91171-7_1

Rane, D. B. (2011). Good listening skills make efficient business sense. The IUP Journal of Soft Skills, 5(4), 43-51.

Rifai, M., Masitoh, S., Bachri, B. S., Setyawan, W. H., Nurdyansyah, N., \& Puspitasari, H. (2020). Using Electronic Design Automation and Guided Inquiry Learning Model in Higher Engineering Education. Universal Journal of Educational Research. https://doi.org/10.13189/ujer.2020.080723

Setyawan, W. H. (2017). Pemanfaatan Teknologi Mobile Learning dalam Pengembangan Profesionalisme Dosen. Al-Ulum, 17(2), 389-414.

Setyawan, W., Rusijono, M., \& Jannah, M. (2018). T-Mobile Learning Android Model-Based to Improve Students' Listening Capability. 1st International Conference on Education Innovation (ICEI 2017). https://doi.org/10.2991/icei-17.2018.96

Soeprajitno, E. D., Setyawan, W. H., \& Wihara, D. S. (2019). Dampak Pelatihan "Service Excellence" Terhadap Kinerja Karyawan Bank Perkreditan Rakyat (Bpr) Kota Kediri. Jurnal MEBIS (Manajemen Dan Bisnis), 4(2), 94-102. 
http://ejurnal.pps.ungac.id/index.php/Aksara 